\title{
Assessing the youth-friendliness of youth clinics in northern Sweden: a survey analyzing the perspective of the youth
}

Anna-Karin Waenerlund ${ }^{1}$, Miguel San Sebastian', Anna-Karin Hurtig ${ }^{1}$, Maria Wiklund ${ }^{2}$, Monica Christianson ${ }^{3}$ and Isabel Goicolea ${ }^{1 *}$

\begin{abstract}
Background: Sweden has nearly 300 youth clinics that have been offering services since the 1970s. However, no evaluation has been done to assess their youth-friendliness. This study aims to assess: i) to what extent youth clinics are perceived as youth-friendly by the young people using them; and ii) if the level of youth friendliness is equally perceived across different sociodemographic groups of users.

Methods: The four northernmost counties of Sweden were included in the study. Of the total identified 22 youth clinics, 20 participated by giving out questionnaires to the youth after their visits to the respective youth clinics. In total 1110 youth participated in the study and answered questions according to the World Health Organization's criteria of accessibility, equity, respect, privacy and confidentiality, no judgement, and quality. Means and frequencies were calculated, and t-test and ANOVA were used to compare means by sociodemographic variables.

Results: Participants perceived the youth clinics as very youth friendly across the measured domains, with scores as high as 4.8 and 4.9 (of a maximum of 5). Youth clinics were perceived in a similar way regardless of gender, but other sociodemographic factors influenced some of the domains, especially ethnic background.

Conclusions: The perception of youth friendliness in youth clinics was very high. Nonetheless, younger users; users who did not categorize themselves as either heterosexual, homosexual, or bisexual; users with trans-experiences; and users with non-Swedish backgrounds gave youth clinics lower scores for certain domains.
\end{abstract}

Keywords: Youth clinic, Sweden, Youth friendly, Health services, Health service accessibility, Youth, Questionnaire

\section{Background}

Health care services can play an important role in the promotion of youth health; they can offer information and care to youth and promote healthy behaviour [1-3]. However, in order to play such a beneficial role, young people have to access such services and receive care that is judged to be of good quality and relevant for their needs; what the World Health Organization (WHO)

\footnotetext{
* Correspondence: isabel.goicolea@umu.se

'Department of Epidemiology and Global Health, Umeå University, 90187 Umeå, Sweden

Full list of author information is available at the end of the article
}

conceptualizes as youth friendly health care services [3]. In order to be youth-friendly, services should fulfil the criteria of being accessible, acceptable, equitable, appropriate, and effective for different youth subpopulations $[3,4]$. While WHO defines youth as those between 15 and 24 [5], the Youth Law (2004) of Sweden defines youth as those between 13 and 25 years.

While interventions to make services more youthfriendly have been implemented in many settings, few countries have truly integrated such an approach in a sustainable way within the health care system $[2,6,7]$. Head Space in Australia has implemented around 100 
clinics, the Jigsaw clinics in Ireland account for 10 and Canada has around 12 of such services [8,9], all of them with a special focus on integrating first line mental health care for young people. Sweden, on the other hand, has around 300 youth clinics (YCs) spread across the country and with more than 40 years of experience offering differentiated services for adolescents and youth $[7,10,11]$. While the target group of YCs is youth - according to the Swedish Youth Law definition- there are variations between YCs in terms of both lower and upper age limits [11]. According to the guidelines of The Swedish Society for Youth Centres (FSUM), and the perceptions of professionals working on YCs, they constitute an example of youth-friendly services [12]. Moreover their integration within the health system, while at the same time keeping a certain level of autonomy, makes them a good case for how youth-friendly services can be sustained within a broader health care system [11].

However, YCs are not without challenges. For example, it is well known that young women outnumber young men in YCs' consultations, and professionals working in YCs point out that inequities might exist in terms of lack of access for certain groups of youth, such as LGBTQ and non-Swedish youths [11]. Also, the resources available differ geographically. YCs located in smaller places have fewer professionals and much shorter working hours, and many rural municipalities lack YCs [11, 13]. While YCs have always implemented a holistic youthcentred approach, the traditional focus has been on sexual and reproductive health. How to strengthen the role of YCs in other areas of health, especially mental health, is currently being discussed [13-15].

Despite the long history of YCs in Sweden, and even if there are internal reports stating that young people using the YCs are in general satisfied with the services provided [12], there is no published evaluation assessing to what extent YCs fulfil the domains of youth-friendliness, and whether these domains might vary for different youth subpopulations. Thus, this study had two objectives: i) to assess to what extent youth clinics were perceived as youth-friendly by the young people using them, and ii) if the level of youth-friendliness was equally perceived across different sociodemographic groups of users.

\section{Methods}

\section{Study design and participants}

This study was conducted in the four northernmost counties of Sweden, namely Jämtland-Härjedalen, Norrbotten, Västerbotten, and Västernorrland. Northern Sweden is a sparsely populated area; while accounting for $60 \%$ of Swedish land, it is home to only $12 \%$ of the population. Most people are clustered in the coastal regions whilst fewer people are situated inland. We focused on this region because it remains under-researched and its rurality better reflects the situation of other rural, scarcely populated areas in the European Union and beyond.

Of the 280 YCs in Sweden at the time of this study, 22 were located in northern Sweden and 20 participated in this study. Youth over the age of 16 who visited one of these 20 YCs were invited to fill in the YFHS-Swe questionnaire after the consultation. The questionnaire was completed in a quiet area at the YCs. The YFHS-Swe questionnaire assesses diverse domains of youth friendliness, based on the YFHS-WHO+ [4] and it has been validated for the Swedish context $[16,17]$.

In September 2016 the questionnaires were sent out to the YCs, and in March 2017 when the data collection ended, a total of 1110 young persons had responded. We excluded 113 responses due to the respondents' being under age 16 or to their declining participation. Only five of the participating YCs kept track of how many youths declined to participate, and their response rate was between 70.3 and $90.9 \%$. For the rest of the YCs, we could not state the response rate.

\section{Measures \\ Youth friendliness}

The YFHS-Swe questionnaire assesses six main domains, namely: accessibility, equity, respect, privacy and confidentiality, no judgement, and quality, of which three have subdomains. The questionnaire can be found in Baroudi et al.'s [16].

Accessibility includes the subdomains of (a) contact (access: contact), (b) sexual and reproductive health (access: sexual), and (c) psychosocial health (access: psychosocial); equity has the subdomains of (a) diversity (equity: diversity) and (b) legal status (equity: legal); and quality has the subdomains of (a) quality of consultation (quality: consultation) and (b) quality of the facility (quality: facility).

All 10 domains and subdomains analysed in this article were assessed using Likert-type scales ranging from $1=$ least youth friendly to $5=$ most youth friendly - the specific items within each question were assessed from 1 to 5 , being $1=$ never present in the clinic to $5=$ always present in the clinic. Table 1 shows a short description of the 10 subdomains contained in the YFHS-Swe questionnaire.

\section{Demographic factors}

Gender was coded as women, men, and other (intergender, non-binary, and other). Trans-experience was dichotomized into yes and no. Sexual orientation included heterosexual, homosexual, bisexual, and other (queer, asexual, I don't categorize myself sexually, I don't know, and other). Place of birth was coded as being born in Sweden or outside the country and parents place of birth was classified as both parents born in Sweden, both born in Europe (but not in Sweden), or at least one of them born outside Europe. 
Table 1 Youth-friendliness subdomains assessed in the YFHSSwe questionnaire (modified from [16])

\begin{tabular}{|c|c|}
\hline Subdomain & Description \\
\hline \multicolumn{2}{|l|}{ Access } \\
\hline Access sexual & $\begin{array}{l}\text { Ability to receive help related to sexual and } \\
\text { reproductive health }\end{array}$ \\
\hline Access psychosocial & $\begin{array}{l}\text { Ability to receive help related to } \\
\text { psychosocial health }\end{array}$ \\
\hline Access contact & $\begin{array}{l}\text { Ability to get contact and ease of accessing } \\
\text { the service }\end{array}$ \\
\hline \multicolumn{2}{|l|}{ Equity } \\
\hline Equity diversity & $\begin{array}{l}\text { Equal terms for youth disregards social or } \\
\text { cultural background, gender, disability or } \\
\text { other }\end{array}$ \\
\hline Equity legal & Equal terms for youth with legal concerns \\
\hline $\begin{array}{l}\text { Privacy and } \\
\text { confidentiality }\end{array}$ & The visit ensured confidentiality and privacy \\
\hline No judgement & $\begin{array}{l}\text { The staff provided attention, support and } \\
\text { were non-judgemental }\end{array}$ \\
\hline Respect & $\begin{array}{l}\text { The youths felt that they are treated with } \\
\text { respect }\end{array}$ \\
\hline \multicolumn{2}{|l|}{ Quality } \\
\hline Quality consultation & $\begin{array}{l}\text { Quality of the encounter between staff } \\
\text { and youth }\end{array}$ \\
\hline Quality facility & Quality of the facility and information \\
\hline
\end{tabular}

\section{Analysis}

To examine the participants' perception of the YCs' friendliness, different scores for each of the domains and the sum of all were created. For each domain, means were obtained by summing up the Likert responses and dividing the results by the number of items in each respective domain. The mean of all of the 10 factor scores was calculated and labelled "Friendliness." Only full cases were analysed, and the response option "I don't know" was excluded. To achieve the second objective, an analysis of variance was performed to assess whether the sociodemographic variables were associated with the mean of the 10 domains. A Bonferroni post-hoc test was also conducted to examine differences between the groups of variables. All analyses were performed in Stata 15.

\section{Results}

Young people responding to the questionnaire were mostly young women (90.7\%), heterosexual (84.4\%), not reporting trans-experiences (98.60\%), born in Sweden (93.99\%), and with both parents born in Sweden (92.59\%). Around one third of participants belonged to each of the different age groups (Table 2). Almost 15\% were visiting the clinic for the first time.

Figure 1 shows that mean scores of youth-friendliness were overall very high. All domains rated above 4. Access: contact had the lowest score (4.1) and non-judgment had the highest (4.9).
Table 2 Characteristics of the participants

\begin{tabular}{|c|c|c|}
\hline & $\mathrm{N}$ & $\%$ \\
\hline \multicolumn{3}{|l|}{ Gender } \\
\hline Women & 985 & 90.7 \\
\hline Men & 93 & 8.6 \\
\hline Other & 8 & 0.7 \\
\hline \multicolumn{3}{|l|}{ Age } \\
\hline $16-17$ years & 348 & 32.7 \\
\hline 18-19years & 325 & 29.3 \\
\hline 20 and $>$ years & 390 & 35.1 \\
\hline \multicolumn{3}{|l|}{ Sexuality } \\
\hline Heterosexual & 937 & 84.4 \\
\hline Bisexual & 82 & 7.4 \\
\hline Homosexual & 9 & 0.8 \\
\hline Other & 59 & 5.3 \\
\hline \multicolumn{3}{|l|}{ Trans-person expression } \\
\hline No & 1059 & 98.60 \\
\hline Yes & 15 & 1.4 \\
\hline \multicolumn{3}{|l|}{ Place of Birth } \\
\hline Sweden & 1032 & 93.99 \\
\hline Outside Sweden & 66 & 6.01 \\
\hline \multicolumn{3}{|l|}{ Place of parents birth } \\
\hline Both in Sweden & 925 & 92.59 \\
\hline Both in Europe & 20 & 2.00 \\
\hline At least one outside Europe & 54 & 5.41 \\
\hline
\end{tabular}

Table 3 shows each domain's mean scores according to the participants' sociodemographic characteristics. No differences were found among most of the variables and the different domains. However, those above 19-years old were more satisfied with access: contact, no judgment, and respect than were the younger groups. Those categorized in the group 'other' regarding their sexual orientation gave lower scores in access: sexual and respect than those who identified themselves as heterosexual, homosexual, or bisexual. Those reporting trans-experiences reported a lower satisfaction with access: sexual, but higher with access: contact.

Youth born outside Sweden reported less satisfaction with access: sexual, equity: diversity, and privacy and confidentiality. In addition to the last two, no judgment, respect, quality: consultation and quality: facility scored lower when at least one of the parents was born outside Europe.

\section{Discussion}

To the extent of our knowledge this is the first study to assess Swedish YCs' degree of youth-friendliness from the perspective of young people using these services. The participants perceived the $\mathrm{YCs}$ as very youth 


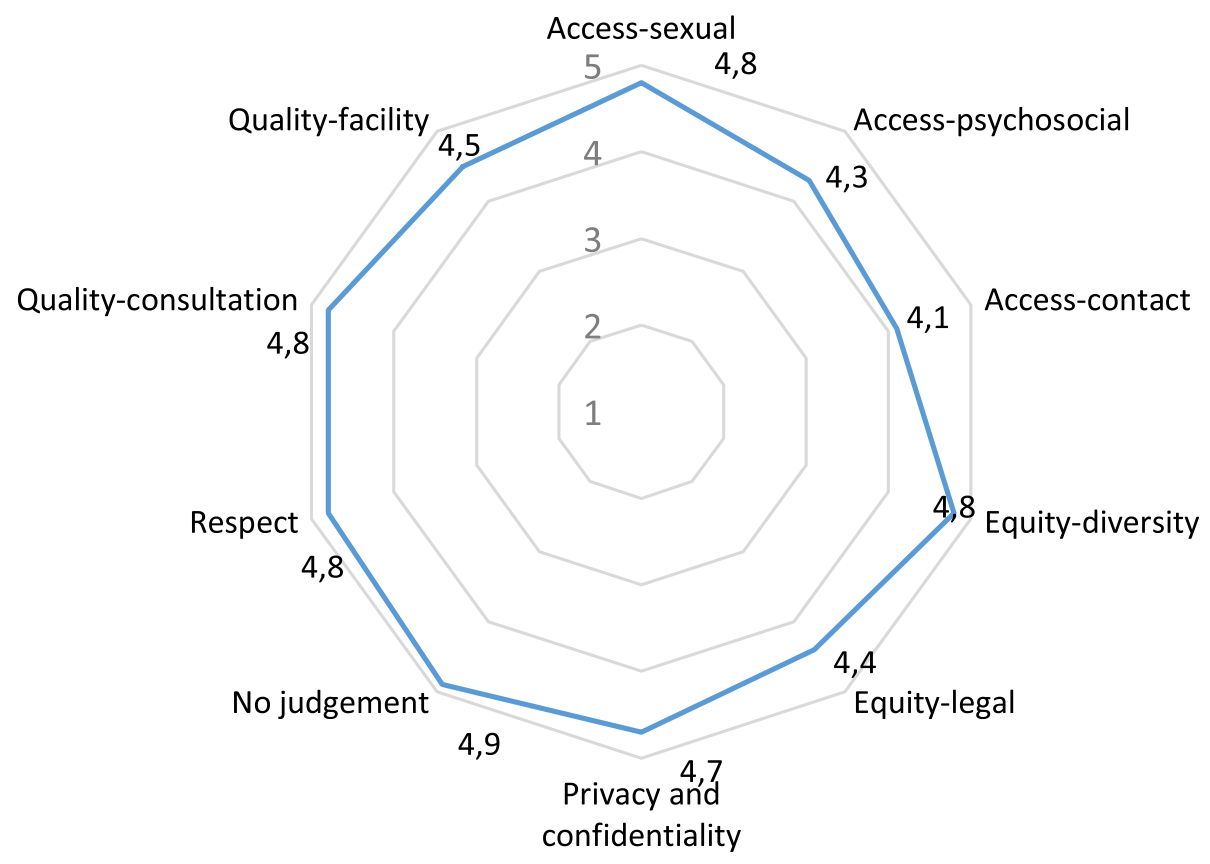

Fig. 1 Mean scores ranging from 1 to 5 for the 10 subdomains of youth friendliness (effective $n=601-976$ )

friendly across the measured domains. YCs were perceived in a similar way regardless of the respondents' gender, but other sociodemographic factors influenced some of the domains.

The YCs were overall assessed very positively by the young people answering the questionnaire. This is an important finding that allows us to label northern Swedish YCs as a good example of youth-friendly services. There are, to the best of our knowledge, no similar studies in other countries to compare with so far. However, during the validation of the YFHS+ questionnaire with primary health care centres in Bosnia-Herzegovina, the scores were considerably lower there [4]. Results from our study confirm previous unpublished evaluations from FSUM and findings from qualitative studies that stress that the "special" youth-centred approach of YCs and the motivation of the staff working on these services make them accessible, acceptable, and appropriate for young people $[11,12]$. Since there are few examples of existing and sustained youth-friendly services in Europe [18, 19], the lessons learnt from the Swedish YC model can inspire efforts in other countries.

In terms of differences based on the sociodemographic characteristics of youths, it is interesting to highlight that there were no significant differences based on gender. Studies, and routine data from YCs' consultations (and even the composition of our sample) highlight that girls and young women outnumber boys and young men in consultations in YCs [20]. This is a pattern not only for Swedish YCs, but for youth-friendly health care services in general. This study, however, also points out an interesting finding: when it comes to those youths actually attending YCs, boys and young men (and also those who do not categorize themselves in gender binary ways) perceive all domains of YCs as high as do girls and young women.

In relation to girls and young women it is also important to note that they rate YCs high in the different domains of youth friendliness. It is known that teenage girls and young women take high responsibility for sexual health and contraceptives in partner relationships [21]. In addition, young women are overrepresented in sick-leave and self-reported health problems (e.g. mental health problems), as well as in exposure to gender-based and sexualised harassment and violence [22, 23], which is why youth-friendly strategies for continuous, early health promotion are important to develop for these groups.

Sexual orientation was one aspect that influenced how young people perceived YCs. The literature shows that LGBTQ youth face barriers to accessing health care services [24-27]. However, most studies take together as a group all non-heterosexual youths. In our study, there were no significant differences between heterosexual, homosexual and bisexual youths, while queer, asexual and non-sexual youth as well as youth with trans experiences rated YCs' differently-and generally lower. This could reflect the fact that while training, LGBTQ certifications, and other efforts might have had an impact in how health care services for youth address sexual 


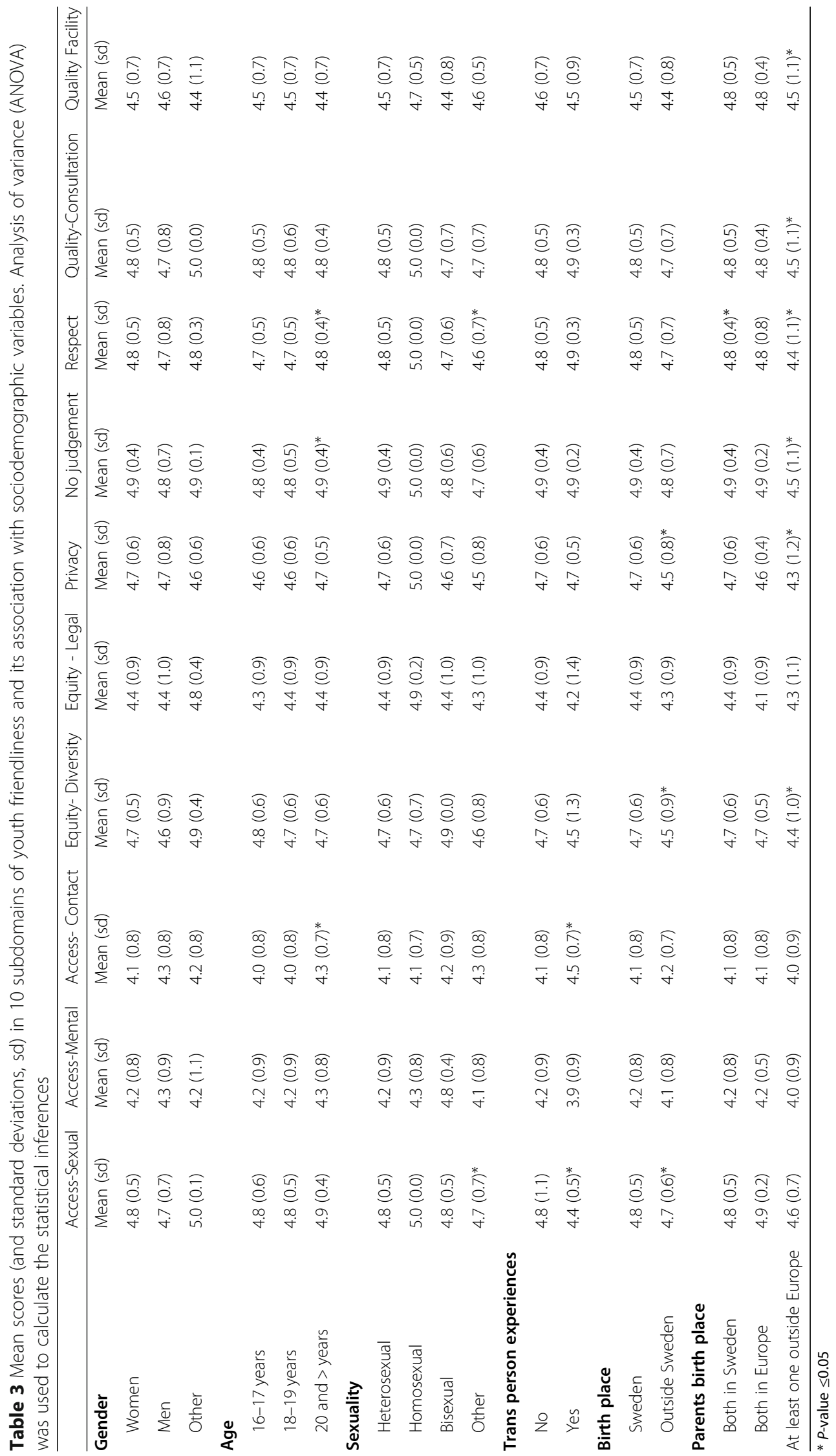


diversity, youth with less normative sexualities (beyond the heterosexual, homosexual, bisexual categorizations) still face increased barriers for accessing services.

The young people's, and especially their parents', country of birth were the variables that were most strongly associated with YCs' lower rating in the different domains. The literature shows that migrants might face more barriers to accessing health care services, based on individual characteristics -e.g. socioeconimc status, language and information barriers -and, especially based on factors at the health-system level -e.g, policies that restrict access, and health care professionals' attitudes, such as discrimination and racism [28-31]. Despite equity being in the core of the YCs' mandate, previous studies have highlighted that YCs' staff perceive that non-Swedish young people access YCs to a lesser extent [11]. This study goes further, pointing out that for those young people with a non-Swedish background who actually reach YCs, their perceptions of the services are also a bit poorer.

Equity is a domain of youth-friendliness that other studies show as being among the most difficult to fulfil $[2,6,11]$. While previous population-based studies have already pointed out that there are socioeconomic inequities in accessing YCs in Sweden [32], and YC staff's perceptions support the hypothesis that certain sub-groups of young people access YCs much less [11, 12, 32], this study reveals that sexual orientation and especially ethnic background are markers of inequities when it comes to YCs' youth-friendliness.

According to the new proposed model by WHO, it is not only a matter that specific, differentiated services should be friendly towards young people, but that the entire health system should embrace such an approach [33]. It would be interesting to apply the YFHS-Swe questionnaire to other health care services that also assist young people in Sweden (primary health care services, youth psychiatry, school health) in order to assess whether they are equally youth friendly.

Finally, it is important to highlight that the sample does not represent the overall young population in Sweden (women, heterosexual, born in Sweden youth are overrepresented). We hypothesize that this, more than being a bias in the selection of the participants, is a reflection of who access youth clinics, and who does not. Special attention should therefore be given to implement strategies to improve access to certain subgroups of young people who might be in more need but accessing clinics less. There are a number of strategies in place when it comes to improving access to certain subgroups of youth, i.e. LGBTQ certification of clinics, visits of students when they are in 9th grade (15-16 years), tailored information and specific drop-in hours addressing those identifying themselves as boys/young men, and certain clinics collaborate with organizations working with unaccompanied youth. However, we claim that more measures need to be taken, including better promotion of the existence and services provided in YCs for all young people, especially for rural youth and those who have moved to Sweden recently and might not be familiar with the services. Crucial is also to remove any barriers related to payment (i.e. for young people who have not been granted legal residence). To date, there are some promising initiatives to overcome barriers and improve access such as the possibility to receive support via digital technologies (i.e. psychologist), including a webbased youth health clinic which is partly translated to additional languages (www.youmo.se).

\section{Methodological considerations}

The distribution of the questionnaires within the YCs might have differed and youth who were perceived to be less satisfied or who were not fluent in Swedish might have been excluded. Internal missing was evident in most questions. This study was only able to capture the visiting youths' perceptions, and not other youths' perceptions. Moreover, we were not able to gather information on how many young people declined to answer the survey and their sociodemographic characteristics.

\section{Conclusions}

For all the youths participating in the study, the perception of youth friendliness in YCs was very high, scoring almost the maximum for access: sexual, equity: diversity, privacy and confidentiality, no judgement, respect, and quality: consultation. YCs received lower scores in certain domains from younger users; from those who did not categorize themselves as either heterosexual, homosexual, or bisexual; from those with trans-experiences; and from those with non-Swedish backgrounds.

The use of the WHO criteria and the YFHS-Swe questionnaire is a good, promising way to scrutinize additional services that meet youth in their daily practices (such as primary care, psychiatry, school health services, paediatric clinics, pain rehabilitation clinics, stress clinic, dental care, etc.).

\section{Abbreviations \\ FSUM: Föreningen för Sveriges Ungdomsmottagningar (Swedish Association of Youth Clinics); LGBTQ: Lesbian Gay Bisexual Trans Queer; WHO: World Health Organization; YC: Youth Clinic; YFHS-Swe: Youth Friendly Health Services Sweden; YFHS+: Youth Friendly Health Services Plus}

\section{Acknowledgements}

We acknowledge all the managers, professionals and young people at youth clinics who administered and fill in the questionnaire.

\section{Authors' contributions}

AKW coordinated the data collection and lead the analysis, together with IG and MS. AKW developed the first draft of the manuscript and together with IG gathered the comments from all team members in order to revise

successive drafts and develop and submit the final draft of the manuscript to 
the journal. MS, MC, MW, AKH all contributed with ideas, and were involved in discussing the findings. They all read and critically commented and revised the successive drafts of the manuscript and approved the final version before submission to the journal.

\section{Funding}

The author(s) disclosed receipt of the following financial support for the research, authorship, and/or publication of this article: This work was supported by FORTE, the Swedish Research Council for Health, Working Life and Living Conditions through a competitive call (registration number 2014-0235). Open access funding provided by Umea University.

\section{Availability of data and materials}

The datasets used and/or analysed during the current study are available from the corresponding author on reasonable request.

\section{Ethics approval and consent to participate}

The ethical approval to apply the questionnaire was granted in August 2015 by the Regional Ethical Review Board Umeå (Drn:2015-190-31Ö). Written informed consent was obtained from each participant. All participants were 16 years old or older, which in Sweden is considered an age were young people can consent to participate in research without the need for consent from legal guardians.

\section{Consent for publication}

Not applicable

\section{Competing interests}

The authors declare that they have no competing interests.

\section{Author details}

${ }^{1}$ Department of Epidemiology and Global Health, Umeå University, 90187 Umeå, Sweden. ${ }^{2}$ Department of Community Medicine and Rehabilitation, Physiotherapy, Umeå University, Umeå, Sweden. ${ }^{3}$ Department of Nursing, Umeå University, Umeå, Sweden.

\section{Received: 31 January 2020 Accepted: 5 April 2020}

Published online: 23 April 2020

\section{References}

1. Chandra-Mouli V, Chatterjee S, Bose K. Do efforts to standardize, assess and improve the quality of health service provision to adolescents by government-run health services in low and middle income countries, lead to improvements in service-quality and service-utilization by adolescents? Reprod Health. 2015;13(1):10

2. Tylee A, Haller DM, Graham T, Churchill R, Sanci LA. Youth-friendly primarycare services: how are we doing and what more needs to be done? Lancet. 2007:369(9572):1565-73.

3. World Health Organization. Making health services adolescent friendly: Developing national quality standards for adolescent friendly health services. Geneva: Report, World Health Organization; 2012.

4. Haller DM, Meynard A, Pejic D, et al. YFHS-WHO+ questionnaire: validation of a measure of youth-friendly primary care services. J Adolesc Health. 2012; 51(5):422-30.

5. Sundby J. Young people's sexual and reproductive health rights. Best Pract Res Clin Obstet Gynaecol 2006;20(3):355-368.

6. Ambresin A-E, Bennett K, Patton GC, et al. Assessment of youth-friendly health care: a systematic review of indicators drawn from young people's perspectives. J Adolesc Health. 2013:52(6):670-81.

7. Baltag $V$, Mathieson A. Youth-friendly health policies and services in the European region: sharing experiences. Geneva: Report, World Health Organization; 2010

8. Malla A, lyer S, McGorry P, Cannon M, Coughlan H, Singh S, et al. From early intervention in psychosis to youth mental health reform: a review of the evolution and transformation of mental health services for young people. Soc Psychiatry Psychiatr Epidemiol. 2016:51(3):319-26.

9. Hetrick SE, Bailey AP, Smith KE, Malla A, Mathias S, Singh SP, et al. Integrated (one-stop shop) youth health care: best available evidence and future directions. Med J Aust. 2017;207(10):S5-s18.
10. Swedish Society for Youth Centres (FSUM). Riktlinjer för Sveriges ungdomsmottagningar [Guidelines for Swedish Youth Clinics], 2015. http://www. fsum.nu/wp-content/uploads/2018/03/guidelines_1.pdf (Accessed 16 May 2019).

11. Thomée S, Malm D, Christianson M, et al. Challenges and strategies for sustaining youth-friendly health services - a qualitative study from the perspective of professionals at youth clinics in northern Sweden. Reprod Health. 2016;13(1):147.

12. Swedish Society for Youth Centres (FSUM). 'Ni är grymma' ('Keep up the good work'), 2015. www.fsum.org/fsum/wp-content/uploads/2011/02/ statistik.pdf (Accessed 26 Sept 2018).

13. Goicolea I, Ahlin $\mathrm{CH}$, Waenerlund $\mathrm{A}-\mathrm{K}$, et al. Accessibility and factors associated with utilization of mental health services in youth health centers. A qualitative comparative analysis in northern Sweden. Int J Mental Health Syst. 2018;12(1):69.

14. Swedish Society for Youth Centres (FSUM). Ungdomsmottagningen i första linjen för psykisk (o)hälsa [The youth clinics in first line mental health]. Stockholm: Report, FSUM; 2018

15. Uppdrag Psykisk Hälsa. Psykisk hälsa på ungdomsmottagningen- en kartläggning av Sveriges ungdomsmottagningar [Mental health in youth clinics - a mapping of Swedish youth clinics]. Stockholm: Uppdrag Psykisk Hälsa; 2017.

16. Baroudi M, Waenerlund AK, San Sebastian M, et al. Assessing the dimensionality of YFHS-Swe: a questionnaire to assess youth-friendliness in differentiated health services. Glob Health Action. 2017:10(1):1380399.

17. Malm D, Bishop L, Gustafsson $P$, et al. Validation of a questionnaire to measure youth-friendliness of Swedish youth clinics. Scand J Public Health. 2017:45(4):366-72

18. Kempers J, Ketting E, Chandra-Mouli V, et al. The success factors of scalingup Estonian sexual and reproductive health youth clinic network-from a grassroots initiative to a national programme 1991-2013. Reprod Health. 2015;12(1):1

19. Kempers J, Ketting E, Lesco G. Cost analysis and exploratory costeffectiveness of youth-friendly sexual and reproductive health services in the Republic of Moldova. BMC Health Serv Res. 2014;14(1):316.

20. Abrahamsson K, Sundin C. Where have all the young men gone? En problematisering av den låga andelen unga män bland ungdomsmottagningens besökare, 2008. https://gupea.ub.gu.se/handle/2 077/18254 (Accessed 19 May 2019).

21. Wigginton $B$, Harris ML, Loxton $D$, et al. Who takes responsibility for contraception, according to young Australian women? Sex Reprod Healthc. 2018;15:2-9.

22. Wiklund M, Malmgren-Olsson E-B, Bengs $C$, et al. "He messed me up": Swedish adolescent girls' experiences of gender-related partner violence and its consequences over time. Violence Against Women. 2010;16(2):207-32.

23. Wiklund M, Bengs C, Malmgren-Olsson E-B, et al. Young women facing multiple and intersecting stressors of modernity, gender orders and youth. Soc Sci Med. 2010;71(9):1567-75.

24. Acevedo-Polakovich ID, Bell B, Gamache P, et al. Service accessibility for lesbian, gay, bisexual, transgender, and questioning youth. Youth Soc. 2013; 45(1):75-97.

25. Hoffman ND, Freeman K, Swann S. Healthcare preferences of lesbian, gay, bisexual, transgender and questioning youth. J Adolesc Health. 2009;45(3): 222-9.

26. Knight R, Shoveller J, Carson A, et al. Examining clinicians' experiences providing sexual health services for LGBTQ youth: considering social and structural determinants of health in clinical practice. Health Educ Res. 2014; 29(4):662-70.

27. Lindroth M, Zeluf G, Mannheimer LN, et al. Sexual health among transgender people in Sweden. Int J Transgen. 2017:18(3):318-27.

28. Kalengayi FKN, Hurtig A-K, Ahlm C, Ahlberg BM. "It is a challenge to do it the right way": an interpretive description of caregivers' experiences in caring for migrant patients in Northern Sweden. BMC Health Serv Res. 2012; 12(1):433

29. Mladovsky P. A framework for analysing migrant health policies in Europe. Health Policy. 2009;93(1):55-63.

30. Padilla B, Miquel JP. Health and migration in the European Union: Building a shared vision for action. Health and migration in the European Union: better health for all in an Inclusive Society. 2009(1a):15-22.

31. European Union. Agency for Fundamental Rights. Inequalities and multiple discrimination in access to and quality of healthcare. Viena: Report, European Union Agency for Fundamental Rights; 2013. 
32. Mosquera PA, Waenerlund A-K, Goicolea I, et al. Equitable health services for the young? A decomposition of income-related inequalities in young adults' utilization of health care in northern Sweden. Int J Equity Health. 2017:16(1):20

33. World Health Organization. Health for the world's adolescents: a second chance in the second decade: summary. 2014. https://apps.who.int/iris/ handle/10665/112750 (Accessed 16 May 2019).

\section{Publisher's Note}

Springer Nature remains neutral with regard to jurisdictional claims in published maps and institutional affiliations.

Ready to submit your research? Choose BMC and benefit from:

- fast, convenient online submission

- thorough peer review by experienced researchers in your field

- rapid publication on acceptance

- support for research data, including large and complex data types

- gold Open Access which fosters wider collaboration and increased citations

- maximum visibility for your research: over $100 \mathrm{M}$ website views per year

At $\mathrm{BMC}$, research is always in progress. 